\title{
Kant's Transcendental Turn as a Second Phase in the Logicization of Philosophy
}

\author{
Nikolay Milkov
}

This paper advances an assessment of Kant's Critique of Pure Reason made from a bird's eye view. Seen from this perspective, the task of Kant's work was to ground the spontaneity of human reason, preserving at the same time the strict methods of science and mathematics. Kant accomplished this objective by reviving an old philosophical discipline: the peirastic dialectic of Plato and Aristotle. What is more, he managed to combine it with logic. From this blend, Kant's transcendental idealism appeared as a new logic that paralleled Aristotle's syllogistic logic. The first result of this move was that philosophy became a formal study that treats even such subjects as ethics with rigour. Another outcome was that it established philosophy as a professional - school - discipline. In the twentieth century academy, this development was echoed by the emergence of analytic philosophy, in which Kant's new logic evolved into a philosophical logic.

\section{Opening}

Some twenty years ago the "new phenomenologist" Hermann Schmitz raised the question, "What did Kant really want?" (Was wollte Kant?) His answer was that the prime objective of Kant's critical philosophy was to theoretically ground the spontaneity of reason. ${ }^{1}$

This paper builds upon Hermann Schmitz's thesis. Indeed, in his Critique of Pure Reason (KrV) Kant did want to secure the spontaneity of reason. Unfortunately, Schmitz failed to specify the theoretical resources which Kant used in order to carry out this task. The first objective in what follows here is to fill this gap. In particular, the aim is to reveal a neglected side of Kant's project of making philosophy a free activity of reason. What will be demonstrated is that in Kant's theoretical philosophy, the spontaneity of reason appears in the form of a recurrent examin-

1 Cf. Schmitz, Hermann: Was wollte Kant? Bonn 1989, 365. 
ing of human knowledge. Further, we shall see that one can view this conception as a recasting of the Platonic project for peirastic dialectic. Finally, and most importantly, the present paper shows that Kant's novel variant of peirastic dialectic was married to logic. An important consequence of this unity was that it helped him to logicize all philosophy, including ethics and aesthetics.

Moreover, Kant's move will appear as the second phase of a tripartite diachronic process of logicization of philosophy. The first historical phase originated in Antiquity when Aristotle logicized Plato's peirastic dialectic - a development discussed briefly in $\$ 2$. The main body of the paper, $\$ \$ 3$ and 4, will be occupied with analysis of the second, Kantian phase of the logicization of philosophy. In particular, we shall see that Kant's logical revolution in philosophy was in many ways related to that of Aristotle. Finally, $\$ 5$ turns to the story of how analytic philosophy stands as a third phase of doing philosophy in logical terms. This culminating point of the paper opens a new dimension for investigating the roots of the early analytic philosophy.

\section{First phase of the logicization of philosophy}

A great bifurcation in philosophy took place in Antiquity in the works of Plato and Aristotle. Roughly, it was a bifurcation between critical philosophy and logical philosophy. How did this come about?

At the beginning, Plato (Plato's Socrates) conceived of philosophy as peirastic dialectic. The latter can be defined as examination of a situation about which we are ignorant; this can be any suggested argument or theory, but also facts or events under consideration. ${ }^{2}$ The objective was to select the best argument or theory among many others. It also deserves notice that Plato's method of examination was connected with his method of division, or analysis. ${ }^{3}$

Soon, however, he started to look for a rigorous, "formal science" (Prol, AA 04: 262) that could do this job with greater confidence. Plato found it in the Forms, which are supposed to be the subject of

2 Cf. Urmson, J. O.: The Greek Philosophical Vocabulary. London 1990, 127; Aristotle, Soph.El., 165a38, $171 \mathrm{~b} 4$.

3 On Plato as the discoverer of analysis, both in mathematics and in philosophy, see Sayre, Kenneth: Plato's Analytic Method. Chicago 1969. 
this autonomous type of inquiry. In fact, this was the first effort to systematize peirastic dialectic.

Plato's task was taken up by Aristotle. Above all, he fused the discipline of truth-seeking (peirastic) with the Theory of Forms into a Theory of General Kinds. This blending found expression in his Categories. The next step was the discovery of syllogism. ${ }^{4}$ It was made by blending the Theory of Forms - central to both Plato and to Aristotle's Categories with the method of division (analysis) into a new discipline. The novelty was that whereas the method of division accepted that the middle term of a judgment is universal, the syllogistic method claimed that the middle term must be subordinated to the first and third terms. Of course, Aristotle's syllogistic logic did not have the heuristic power of the peirastic method. In compensation, though, it was far more rigorous.

This move had two important results: (i) Ontology became more formal; more specifically, the Theory of Forms was replaced by an investigation of being qua being, or the "logical forms." The resulting autonomous discipline was subsequently called metaphysics. (ii) The new science of logical forms radically diminished the prominence of mathematical knowledge in the eyes of both philosophers and mathematicians. The reason for this change was that metaphysics was now conceived as an alternative formal discipline in a way more fundamental than mathematics. This belief was abandoned only in the late sixteenth and the early seventeenth centuries when Vietae and Descartes rediscovered the practice of (mathematical) analysis and made it autonomous again.

\section{Kant's rediscovery of peirastic dialectic}

\subsection{Introduction}

Kant was the greatest synoptic thinker in the history of philosophy. This is clear in his masterpiece, $\mathrm{KrV}$, in which he deduced all a priori concepts from a single principle and within one system. His synoptic thinking was not only logical, however, it was historical as well. Indeed, it has been claimed from the beginning that $\mathrm{KrV}$ was an attempt to combine the empiricist and rationalist traditions in philosophy. What follows is principally concerned with another side of Kant's historically synoptic thought: his

4 On the discovery of syllogism cf. Ross, W. D.: "The Discovery of Syllogism”. The Philosophical Review 48 (1939), 251-71. 
integration of the two philosophical disciplines just mentioned, viz., peirastic dialectic (which, as we shall presently see, he referred to as "criticism") and syllogistic logic, which two had been kept separate for more than 2000 years.

Apparently, this step of Kant's was prompted by the publication in 1765 of Leibniz's Nouveaux Essais. ${ }^{5}$ Leibniz argued that the "new philosophers [above all Descartes and Locke] have carried the reform [of philosophy] too far." Instead, he pleaded, "to rehabilitate the old philosophy and restore the all but banished substantial [logical] forms." Kant was deeply impressed by Leibniz's appeal.

Recall that in the early 1760 s Kant was widely known to be a brilliant analyst. When in 1763 the Prussian Academy of Science in Berlin organised a philosophic competition asking "Are the metaphysical truths at all open for the clear proofs of geometry?", he won the second price (the first price went to Moses Mendelssohn). After Kant read Leibniz's Nouveaux Essais, however, he experienced a change of heart - he turned back to the Greeks. He did not, however, stay with the Aristotelian substantial forms, as Leibniz advised. Instead, Kant revived a long forgotten philosophical subfield - the peirastic dialectic. As we have noted, Plato discovered the latter, which Aristotle developed further, even as he rendered it fairly toothless in the process (in the sense that it lost its heuristic power). In the Middle Ages it was extensively discussed but often misunderstood and misinterpreted. After the analytical revolution of Vietae and Descartes, which restored the importance of mathematics, it was entirely forgotten. But not in Germany, however. It was preserved there in the seventeenth century, in Königsberg, where Kant came upon it in the eighteenth century. ${ }^{6}$

To be more specific, in KrV Kant managed to transform the old discipline of peirastic dialectic above all into the idea that human knowledge recurrently tests its origins. By such testing, the subject is free to decide what is to be preserved as knowledge and what is to be rejected as illusion. ${ }^{7}$ In fact, that is how Kant incorporated the spontaneity of reason

5 Cf. Tonelli, Giorgio: "Das Wiederaufleben der deutsch-Aristotelischen Terminologie bei Kant während der Entstehung der Kritik der reinen Vernunft". Archiv für Begriffsgeschichte 9 (1964), 234.

6 Cf. Tonelli, op. cit., 241.

7 This point is emphasized in Robert Brandom's paper "Kant on Judgement and Representation", published in these Proceedings. He argues that judgment is an activity of synthesizing new endorsements with the old endorsements. Further- 
into philosophy (Hermann Schmitz's problem from $\$ 1$ ), making it an indispensable part of the latter. In doing so, he substantiated it theoretically.

In Kant's applied philosophy (which is not the subject of this study) the critical practice of peirastic dialectic found expression in the exercise of ethical freedom. Finally, it was articulated in Kant's famous dictum that we cannot learn philosophy but only learn to do philosophy (A 837/B 865). To be more precise, we do philosophy differently every time, depending on the state of affairs or the argument with which we are confronted and which we are to assess (judge).

\subsection{Epistemological peirastic dialectic}

The origin-testing, or "critique", of human knowledge is realized in $\mathrm{KrV}$ on three levels: perception, understanding, and reason:

(a) Perception. In our perception we synthesize noumena with forms. More especially, every judgement of perception tests the matter which affects our senses so that the subject chooses certain elements out of the multiplicity of the matter - disregarding other elements - and orders them in a certain form.

(b) Understanding. Kant was adamant that our understanding (grasping) is not merely a calculation. The mere picking out of data from experience and putting them in accurate forms is not enough in order to receive new knowledge. Rather, by every act of grasping individuals and facts we also penetrate "to [the] empirical or experimental conditions of their application", test them, and accept only those of them which we assess (judge) as objective, while rejecting others as subjective or false.

(c) Reason. The peirastic (examining) character of human knowledge is especially prominent in human reason in the following way. Pure reason operates with ideas. Ideas, however, have not a constitutive function but rather a regulative one. This means that they do not refer to objects. To be more specific, ideas are formulae for a perspectival conceiving of objects. The great mistake of the pre-critical metaphysics consisted in the fact that it followed the inclination of human reason to use ideas as if they referred to objects. For example, metaphysicians either claimed that space and time are infinite, or that they are finite objects. In reality,

more, since the judgments are the minimal units of normativity, the subject is responsible for their construction. 
space and time are neither finite nor infinite. They are only intuitions, constructed with the help of rules for adding, or dividing, points of space, or moments of time.

\section{Second phase of the logicization of philosophy}

\subsection{Kant's transcendental idealism as new logic}

The conventional wisdom has it that the Aristotelian syllogistic played only a subordinate role in Kant's system: it simply served as a canon for assessing human knowledge. ${ }^{8}$ In a sense, this claim is correct and can be supported with abundant passages from $\mathrm{KrV}$. The present section, however, details the relation between them. Articulating this relation opens a new, broader perspective on Kant's magnum opus.

Moreover, we claim that Kant's project for transcendental idealism was no less than an advancement of a new formal discipline in philosophy: of a new - transcendental - logic, which outlines the capacities of pure reason. It was formal in the sense that it set the scope and validation of the a priori functioning of thinking (understanding) and of the way in which it is connected with material content. Its final objective was to advance "a complete table of the moments of thinking in general" $(\mathrm{KrV}$, A 71/B 96).

Furthermore, Kant's new logic can be seen as a synthesis of (syllogistic) logic and peirastic dialectic; by means of this synthesis it created a logical system of the practice of examining. Arguably, with this act Kant accomplished something similar - although on a new level - to what Aristotle did in regard to Plato's peirastic dialectic when he launched his syllogistic logic (cf. $\$ 2$, above).

Despite the fact that Kant's new discipline was formal and so contentless, in another respect it was a real program for contentful, or philosophical, logic. This is so because the procedure for examining the forms of human understanding, which is intrinsically connected to its content (or matter), was central to it.

8 Cf. Peckhaus, Volker: Logik, Mathesis universalis und allgemeine Wissenschaft. Berlin 1997,115 . 


\subsection{Kant's new logic as transformation of Aristotle's syllogistic}

Listed below are four points that support the thesis that Kant's transcendental idealism is closely related to Aristotle's logic:

(i) Both Aristotle and Kant claimed to have discovered a totally new science. Indeed, in antiquity Aristotle identified himself as the originator of the science of syllogistic logic: "I had no predecessors", said he in Soph. El., 184b1-3. Similarly, Kant declared: "This [his transcendental idealism] is a totally new science which nobody has ever thought of" (Prol, AA 04: 262). In the history of philosophy this claim from Aristotle and Kant is more or less unique.

(ii) Similar to Aristotle's syllogistic logic, transcendental idealism claimed that all its elements are intrinsically connected with one another. The point is that all parts of pure reason are organically connected. In consequence, all concepts are transcendentally deducible from one principle (Prol, AA 04: 260).

(iii) Exactly like Aristotle's syllogistic logic, the function of transcendental idealism was to advance a strict system of concepts and principles. It was not devised as ars judicandi. This limited the heuristic power of Kant's philosophy and gave it a peculiar scholastic sway (cf. $\$ 4.3$, below). However, the ingenuity of Kant's philosophy was only seemingly reduced. It received its full realization in Kant's applied philosophy.

(iv) Again like Aristotle with his syllogistic logic, Kant claimed to advance a complete (vollständige) system of principles which would not need any improvement. It is as comprehensive as the grammars of the natural languages.

The relatedness of Kant's transcendental idealism to Aristotle's syllogistic is not difficult to explain. Indeed, in the act of judging - whose norms were articulated in syllogistic form - Kant found "an act of the understanding which comprises all the rest and is distinguished only by various modifications or phrases, in reducing the multiplicity of representation to the unity of thinking in general" (Prol, $\$ 39$ ). More specifically, judgment is a necessary element of all three forms of mental action discussed above, in $\$ 3.2$ :

in perception (in the synthesis of apperception) judgment unifies parts of the multiplicity of the matter in one notion;

in thinking (the synthesis of apprehension) it connects notions in concepts; 
in understanding judgment selects elements of the multiplicity of concepts and gathers them in ideas.

Moreover, besides the systematic relatedness between Kant's new logic and Aristotle's syllogistic, there was apparently also a genealogical one. Our thesis is that Kant derived his transcendental logic from Aristotle. This claim can be supported by the fact - often discussed in the literature - that Kant's table of categories runs in parallel to Aristotle's table of judgments.

\subsection{The aftermath}

The most important consequence of the introduction of Kant's new logic was that it transformed the practice of the traditional metaphysics into a formal discipline: after this turn, philosophers started to treat their problems from a formal point of view. This practice can be called logocentric: it helped to treat philosophical problems with formal method. ${ }^{10}$ It became an idiosyncratic characteristic of German philosophy of the "big nineteenth century" (1789-1914) and had great influence on the early analytic philosophy. Most importantly, the German logocentrism in philosophy was perpetuated even by such declared critics of Kant as Bernard Bolzano.

One effect of this development was the "subsequent unavoidable dryness, and scholastic precision" of philosophy (Prol, AA 04: 262). In short, this was the result of the requirement that philosophy must develop not spontaneously but rather under the control of the new canon. Indeed, Kant was adamant that critical reason "keeps common reason in check and prevents it from speculating” (ibid., 259). It is something like an intellectual police $(\mathrm{KrV}, \mathrm{B} \mathrm{xxv})$ which must keep philosophers away from speculation. ${ }^{11}$ In a similar way, when confronted with it, the intellectuals of the twentieth century, alien to the analytic tradition in philosophy, understood its function as a kind of "philosophical police." This was also the impression of Albert Einstein when he read some of Russell's writings on epistemology.

9 Cf. Wolff, Michael: Die Vollständigkeit der Kantischen Urteilstafel. Frankfurt 1995.

10 H.-J. Glock first spoke of the logocentrism of German philosophy. See his "Vorsprung durch Logik: The German Analytic Tradition”, in: O’Hear, A. (ed.), German Philosophy Since Kant. Cambridge 1999, $142 \mathrm{ff.}$

11 The metaphor of intellectual police is also used in Prol., $\$ 57$. 
Another outcome was the establishing and dominance of professional philosophy in German universities. As a result, "within the 25 years following the publishing of $\mathrm{KrV}$, the great men contemplating the world sub specie aeternitatis vanished from the philosophical scene." ${ }^{\prime 2}$ Characteristically, this process was kindred to what happened after the victory of the early analytical philosophy prevailed in the late 1920s and in the 1930s on the academic scene. The latter development, in turn, was related to the effects that Aristotle's attack had on Plato's dialectics. Indeed, this attack "may usefully be compared with the attempt of the twentieth-century positivists to free science from metaphysics. Aristotle rejects the pretensions of a non-empirical discipline claiming to be a science and to prescribe to the genuine empirical sciences." ${ }^{\prime 3}$ This parallelism is not accidental. What we have here is nothing but the relatedness of the last two phases of the logicization of philosophy discussed in this paper.

\section{Third phase of the logicization of philosophy}

5.1 Early analytic philosophers synthesize logic with peirastic dialectic

At the very end of the nineteenth century and the beginning of the twentieth, the logicization of philosophy came to its third phase. A major role in this process was played by the imposing figures of G. E. Moore, Russell and Wittgenstein.

Kant's new logic was related to the early Cambridge analytic philosophy in four main ways:

(a) Logic as prima philosophia. A main tenet of the early Cambridge analytic philosophers was that logic is prima philosophia: it is determinative of all philosophical disciplines. Russell made this point with particular clarity: "All sound philosophy should begin with an analysis of propositions." " (Philosophical) logic was basic to philosophy for G. E. Moore as well. This is evident, for example, in his concept of the "naturalistic fallacy." For Moore, "good" is a synthetic a priori concept that cannot be defined through reference to facts of the real world. On this matter Moore followed (via Henry Sidgwick) Kant's insistence that freedom is

12 Hegel, Sc. Log., $\$ 26$.

13 Irwin, Terence: Aristotle's First Principles. Oxford 1988, 147.

14 Russell, Bertrand: A Critical Exposition of the Philosophy of Leibniz. Cambridge $1900,8$. 
intrinsically valuable and so "must be conceived as wholly independent of the natural law" (Prol $\$ 53$ ).

An expression of the (very Kantian) assumption that logic is the leading philosophical discipline was the belief of the early analytic philosophers (of Russell of 1914 in particular) that "philosophy [i. e. logic] is a study apart from the other sciences." 15 Exactly like Russell, in the Tractatus (4.111), Wittgenstein insisted that "philosophy is not one of the natural sciences. (The word 'philosophy' must mean something which stands above or below, but not beside the natural sciences.)" This was a clear anti-naturalistic stance, markedly at odds with the Quineian "analytic naturalism" that prevailed in North America during the second half of the twentieth century.

(b) The role of judgment. Exactly as for Kant, for the early analytic philosophers the act of judging was central to philosophy. G. E. Moore, in his "The Nature of Judgement" (1899), accepted that a judgement, or a proposition, is composed of concepts, with a specific relation between them. Concepts are infinite numbers of independent entities with relations between them that are independent as well. This was Moore's relational theory of judgement and reality (he considered them identical).

Moore's theory was replaced by Russell's multiple relation theory of judgement, developed in his famous Theory of Descriptions. It asserts "the existence of individuals with which we are not acquainted. The role of the description is, more precisely, to construct an individual with the help of general terms and concepts, and from pieces of reality with which we were previously acquainted. ... A main role in this constructing is played by the creative selecting and ordering of individuals with which we are acquainted, in order to make the description (construction) of the individual in question. This is nothing more than a form of selecting - in deliberation - what there is." 16

Wittgenstein's central theme was also that of judgement: the picking out of a certain complex a given set of simples. This was a problem he tried to solve in $1915,{ }^{17}$ but failed. When Wittgenstein returned to philosophy in the 1929, he continued to explore the paradox of compositionality (e.g. in his Philosophical Investigations, $\$ 47$ ). His solution was the kaleidoscope principle, or the aspect-changing perceiving of a complex.

15 Idem: Our Knowledge of the External World. London 1914, 240.

16 N. Milkov: A Hundred Years of English Philosophy. Dordrecht 2003, $61 \mathrm{f}$.

17 Cf. Wittgenstein, Notebooks 1914-1916. Oxford 1979, 68. 
At different moments we grasp one of the figurations of the complex, the others remaining in shadow, ${ }^{18}$ and it is up to us - to our judgement - to choose which figuration will be contemplated.

(c) From logic to criticism. The philosophical logic of the early analytic philosophers advanced logical canons, ${ }^{19}$ with the help of which it examined and criticized philosophical and scientific propositions. The most prominent example of this practice was the just discussed Theory of Descriptions, which became the "paradigm of analytic philosophy" (Ramsey) exactly because it suggested such a rigorous device that even Wittgenstein did not criticize it. Generations of analytic philosophers examined traditional metaphysics from this perspective. ${ }^{20}$ In the Tractatus, Wittgenstein too advanced a logical canon in the form of a "general propositional form" (4.47). Finally, the logical positivists overcame the old metaphysics with reference to the canon of "the principle of verification."

(d) Criticism (peirastic dialecticSimilar to Kant's philosophy, early analytic philosophy had a clear peirastic or critical stance. Moreover, at the beginning, analytic philosophy was conceived of as an essentially critical philosophy. ${ }^{21}$ Moore's main task, to begin with him again, was to examine and criticize metaphysical non-demonstratives: to translate the arguments of the traditional philosophers into concrete terms. This was an activity of clarification by which he relied on his own intuition as a highest court of appeal.

Wittgenstein's objective in the Tractatus was similar to that of Moore: testing and examining - i.e., criticizing - the propositions of philosophers, above all, of Frege and Russell. In this sense he defined philosophy as activity, not as theory (4.112). Wittgenstein eliminated in this way the logical constants, the theory of types, the multiple relation theory of judgment, the axiom of infinity, and other theories and arguments. The later Wittgenstein exercised the practice of examining based on inarticulable rules that can be roughly defined as a combination of anti-essentialism and non-reductivism. The general requirement was to oppose third, mediating entities by analysing the contact between two formations (mind and body, proposition and fact, etc.), but at the same time to avoid

18 Cf. Milkov, op. cit., 85.

19 In this respect it was related to syllogistic logic.

20 Martin Heidegger's Was ist Metaphysik?; cf. Carnap, Rudolf: "Überwindung der Metaphysik durch logische Analyse der Sprache". Erkenntnis 2 (1931), 220-241.

21 Cf. Broad, Charles: "Critical and Speculative Philosophy", in: Muirhead, J. H. (ed.), Contemporary British Philosophy, London 1924, 75-100. 
the reduction of one of these formations to the other, or their mutual fusion. ${ }^{22}$

Criticism was also a central motive in Russell's philosophy. Indeed, in The Problems of Philosophy he defined his philosophy as "a criticism of knowledge." 23 It aims at "a critical examination of the grounds of our convictions, prejudices, and beliefs." ${ }^{24}$ In the early 1940s Russell even wrote the paper "The Art of Rational Conjecture." ${ }^{25}$ Philosophers have only recently discovered this side of Russell's philosophy. ${ }^{26}$

\subsection{Analytic philosophy as successor of the transcendental idealism}

Kant's new logic was not simply kindred to analytic philosophy, with many curricular or stylistic similarities between them. In fact, the whole of early analytic philosophy can be seen as a furtherance of Kantian ideas and, more precisely, of his new logic, which investigated philosophical problems with logical means and which substantiated the critical practice of examination. ${ }^{27}$

This point explains why Wittgenstein's philosophy is easily interpreted as Kantian. Indeed, both suggested logical canons and used them as means for criticism - as a "negative touchstone of truth" ( $\mathrm{KrV}, \mathrm{A} 65 /$ B85), the only difference between Kant and Wittgenstein in this respect being "what Kant's transcendental deductions are intended to perform: this is performed [by Wittgenstein] by the logical analysis of language."28

For their part, Oxford ordinary language philosophers rediscovered their philosophy as Kantian. This is clearly seen in "Metaphysics" (1957), a manifesto article of the most promising conceptual analysts of the time: Paul Grice, David Pears and Peter Strawson. These authors made the claim that analytic metaphysics (their sub-discipline of preference) is concerned with the conceptual preconditions of the whole of

22 Cf. Milkov, op. cit., 86.

23 Russell, Bertrand: The Problems of Philosophy. London 1912, 234.

24 Ibid., 239.

25 Cf. Russell, Bertrand: “The Art of Rational Conjecture", in The Art of Philosophizing. Lanham (MD) 1974, 1-36.

26 The first step in this direction was made in Hare, William: "Bertrand Russell on Critical Thinking", Proceedings of the Twentieth World Congress of Philosophy, vol. 3. Boston 1998.

27 Robert Hanna, Kant and the Foundations of Analytic Philosophy. Oxford 2001.

28 Stenius, Erik: Wittgenstein's Tractatus. Oxford 1964, p. 218. 
knowledge, preconditions that were explored comprehensively only by Kant. Investigating the conceptual prerequisites of human understanding is also the main concern in Peter Strawson's Individuals, a book that Strawson himself called "Kantian."

For the attentive historian of philosophy, the crypto-Kantianism of the early analytic philosophy is not surprising.

\section{Epilogue}

At the end of this paper, we would like to make the following remark. In the case of early analytic philosophy, for the first time in the history of philosophy a leading philosophical movement was advanced that was not connected with a proper name. Until that point in time, the world had heard about Platonists, Aristotelians, Thomists and Cartesians. Now, a new nameless philosophy appeared which can be simply called "rigorous philosophy."

The case with Kant was something different. Indeed, his name is the most celebrated in the history of philosophy. At the same time, however, the very fact that Kant was "rediscovered" in the second half of the nineteenth century by the so called "neo-Kantians", and also the zeal with which their enemies fought them, as well as the diversity of the "neoKantians" themselves, suggests that it was not just the philosophy of one person that was at stake. Rather, disputed was the new, logicized philosophy as a type of philosophy. In the fin-de-siècle the latter was rediscovered and reintroduced as "analytic philosophy." At the same time, the "neo-Kantianism" perished, which suggests that this was only a metamorphosis of the new type of philosophy - logicized philosophy - examples of which already existed in antiquity. 
